\title{
Food fights: aggregations of marine hermit crabs (Pagurus samuelis) compete equally for food- and shell-related carrion
}

${ }^{1}$ Department of Biological
Sciences, Dartmouth College,
Hanover, New Hampshire 03755

${ }^{2}$ Department of Integrative Biology, University of California, Berkeley, California 94720.

3 Department of Psychology, University of Cambridge, United Kingdom CB2 3 EB.

${ }^{*}$ Corresponding author email: <mark.laidre@dartmouth.edu>.

Date Submitted: 31 August, 2015. Date Accepted: 26 May, 2016. Available Online: 7 July, 2016.

\author{
Alison L Greggor ${ }^{1,2,3}$ \\ Mark E Laidre ${ }^{1,2}$ *
}

ABSTRACT.-Competition for limiting resources drives animal aggression. Aggression in hermit crabs has been well studied in shell acquisition circumstances, yet less is known about hermit crabs' competitive behavior in other contexts, especially as they relate to feeding. As active foragers, competition for food resources may be a major determinant of hermit crab aggression and fighting behavior, particularly in intertidal marine environments, where protein-rich carrion may be limiting. Here, we measured aggressive, competitive interactions between hermit crabs [Pagurus samuelis (Stimpson, 1857)] that were presented with carrion in the laboratory, immediately after they were collected from the field. Aggregations of three crabs were provided with either mussel or gastropod flesh. Both forms of carrion naturally indicate food availability, though only the latter may correlate with potential shell availability. We found that levels of aggression rose significantly in response to both carrion conditions, but not in response to a control condition involving the introduction of a non-eatable object. Larger individuals displayed the highest levels of aggressive behavior, but levels of aggression did not differ between crabs provided with the gastropod and the mussel flesh. These results reveal that food-independent of a shell resourcecan be a powerful motivator for competitive behavior in hermit crabs. Further studies of food-related aggression between different hermit crab species could shed light on how interspecific competition might lead to potential specializations on different carrion or prey resources.

Aggressive interactions are the result of direct competition for limited resources. Hermit crabs (superfamily: Paguroidea) must acquire an adequate shell to survive, grow, and reproduce (Hazlett 1981, Lancaster 1988, Laidre 2012a). Yet crabs are often constrained by a limited supply of empty shells (Kellogg 1976, Scully 1979, Laidre 2012b). This dependence on shells creates competition, both within and between hermit crab species, because individuals cannot obtain shells directly from living gastropods (Laidre 2011). Hermit crabs therefore fight fiercely for new shells, using well-known aggressive behaviors and stages of fighting (Elwood and Neil 1992).

Individuals that can most quickly locate recently vacated shells and effectively ward off competitors likely have an advantage in obtaining an optimal shell. The 
drive to find new shells should thus favor crabs that actively seek out gastropod predation sites, where new shells first enter the "housing market" (McLean 1974, 1983, Rittschof 1980a, Hazlett et al. 1996, Turra et al. 2005, Tricarico and Gherardi 2006, Tricarico et al. 2009). The presence of highly specific, shell-related cues (released by predatory gastropods during the consumption of smaller, shell-inhabiting prey) is thought to be critical in attracting hermit crabs to these shell-acquisition sites (Rittschof 1980b). Indeed, shells freshly-derived from predated gastropods may be more desirable to marine hermit crabs than shells previously used by conspecifics (Laidre and Trinh 2014).

Shells, however, are not the only limiting resource for which crabs must compete. Consequently, hermit crabs should not solely be attracted to sites that indicate shell availability. As scavengers, hermit crabs must also actively search and acquire patchily-distributed food resources (Britton and Morton 1994, Morton and Yuen 2000, Tran 2014). Recent field experiments have revealed that marine hermit crabs are attracted in extreme abundance, and more quickly than any other tide pool inhabitants, to carrion sites that exclusively indicate potential food (Laidre and Greggor 2015). Moreover, laboratory studies indicate that hermit crabs will signal and fight with models (made from dead postured conspecifics), as well as with live conspecifics, when presented with such carrion (Laidre 2007, Laidre and Elwood 2008). Yet, little is known about how the aggregations of hermit crabs that converge on carrion behave while competing for food; and studies in the field have provided only a crude measure of actual competitive behavior within aggregations around food resources (Laidre and Greggor 2015).

Interestingly, food- and shell-related cues do not always occur in isolation, but may at times overlap, especially soon after gastropod predation events (McGuire and Williams 2010). Moreover, during gastropod predation, the peptides that are thought to act as "shell cues" (Rittschof 1980a,b) are not necessarily always produced. For instance, gastropods that are crushed but whose flesh is not enzymatically degraded would fail to release such "shell cues," at least initially. In such cases, hermit crabs could still benefit from attending to the cruder, more generalized carrion cues, particularly if doing so enabled earlier detection of a valuable food resource. Indeed, those crabs that are attracted to sites where gastropods were recently killed may acquire food, a shell, or even both (Laidre 2011).

Here, we investigated levels of aggression in aggregations of marine hermit crabs, Pagurus samuelis (Stimpson, 1857), that were provided with two different types of freshly-generated carrion: carrion from mussels (which exclusively indicate a food resource) and carrion from gastropods (which indicate food and, potentially, a shell resource as well). In prior experiments that we carried out in the field, hermit crabs were attracted in equal numbers to mussel and gastropod carrion sites (Laidre and Greggor 2015). However, detailed measures of competitive behavior were impossible to record in the field, given the challenging observation conditions within tide pools that crabs inhabit. We therefore utilized a controlled laboratory context in the present study so that we could quantify the extent to which each type of food resource generated competition and fighting behavior. By using hermit crabs that had just been collected from the field, we also ensured that their motivation (Laidre and Elwood 2008) reflected natural hunger levels in the wild. We contrasted the levels and types of aggression that crabs exhibited between the two carrion resources, only one of which may be associated with usable shells. By exploring the influence 
of eatable carrion on specific measures of behavioral aggression, our experiments shed light on hermit crab competitive interactions that occur in a natural foraging context, outside the standard shell-fighting paradigm.

\section{METHODS}

Study Site and Species.-This study was carried out between November 2011 and April 2012 at the Bodega Marine Laboratory, located on the Bodega Marine Reserve in Sonoma County, Northern California. The laboratory occupies a pristine rocky intertidal area, which has been the focus of prior field (Laidre and Greggor 2015) and laboratory (Laidre and Trinh 2014) experiments on marine hermit crabs. Here we focused our study on P. samuelis, the most abundant hermit crab species in the intertidal zone and common along the US west coast. Many other marine invertebrates also inhabit this area (Morris et al. 1980), including the California mussel (Mytilus californianus Conrad, 1837) and the black turban snail [Tegula (Chlorostoma) funebrale A. Adams, 1855] whose shells P. samuelis frequently inhabits (Bollay 1964).

Collecting and Behavioral Experiments.-In total, 60 experiments were conducted ( $n=20$ for each of three different conditions). For each set of experiments, we collected the following from a tide pool: 9 hermit crabs, 1 black turban snail $(C$. funebrale), and 1 mussel (M. californianus). All were immediately brought from the tide pool into the laboratory in $<10 \mathrm{~min}$. Crabs were chosen only if they occupied a black turban shell, had shell diameters measuring 1-2 cm, and had all appendages intact. The nine crabs that we collected for each set of experiments were randomly allocated to three different artificially created aggregations (three crabs per aggregation). Each aggregation was placed into a small glass container $(10 \mathrm{~cm}$ diameter, 5 $\mathrm{cm}$ height), which was filled with seawater from the tide pool. Aggregations were randomly assigned to one of three conditions: rock (control), mussel, or gastropod. For the latter two conditions, we cracked open a live mussel and a live gastropod and removed a piece of flesh $(0.15-0.25 \mathrm{~g})$ from each. For the rock condition, we used a rock (within the same weight range and approximate size) that was chosen at random from a large bucket of rocks collected from the tide pools. The rock was thoroughly washed in water before the experiments so that it was free of any chemical cues.

Once aggregations were placed in their container they were given $30 \mathrm{~min}$ to acclimate before experimentation began. Each experiment lasted a total of $6 \mathrm{~min}$, first involving a 3-min baseline period (to assess competition levels before any resource had been introduced) and then immediately followed by a 3-min test period (to assess competition levels after a resource had been introduced). At the transition moment between the 3-min baseline period and the 3-min test period, we introduced a resource (rock, mussel, or gastropod), dropping it in the center of the container (see Online Supplementary Videos 1-3). During both the baseline and the test period, the aggregations were videoed from above with a camera mounted on a tripod so that the hermit crabs' behavior could be precisely quantified. At the end of each experiment, the shell diameters of all three crabs in each aggregation were measured to $0.01 \mathrm{~mm}$. (Note, of the 60 experiments, four lacked shell measures and were excluded from the individual-level analysis described below). After the experiments were completed, crabs were returned unharmed to their original tide pool. 
Table 1. Definitions of aggressive behaviors of Pagurus samuelis during experimental baseline and test periods examining effects of the addition of carrion on crab behavior.

\begin{tabular}{|c|c|}
\hline Behavior & Definition \\
\hline Leg strike & $\begin{array}{l}\text { Rapid movement of a leg away from one's body and toward another crab, } \\
\text { with contact }\end{array}$ \\
\hline Attempted leg strike & Same as leg strike, except without contact \\
\hline Claw strike & $\begin{array}{l}\text { Rapid movement of a claw away from one's body and toward another } \\
\text { crab, with contact }\end{array}$ \\
\hline Attempted claw strike & Same as claw strike, except without contact \\
\hline Piggyback & Climbing onto the back of a conspecific \\
\hline
\end{tabular}

Video Coding.-Videos were coded for the number of aggressive actions performed by each separate crab within an aggregation. Aggressive interactions (defined in Table 1; cf. Ramsay et al. 1997) were categorized as: striking another crab with a leg or claw, attempted striking (but without making contact), and climbing onto the back of another individual (note: during video coding, one crab was found to be missing one of its claws, thus the rock trial in which it participated was removed from the data set).

Predictions and Statistical Analyses.-We hypothesized that hermit crabs brought immediately from the field into the laboratory would be highly motivated to compete over eatable carrion. In particular, we predicted that the amount of aggression crabs exhibited would increase significantly from the baseline to the test period, both in the gastropod and in the mussel conditions, but not in the rock condition. We also compared the gastropod and mussel conditions to one another. Critically, if crabs are especially hungry in the wild, then any source of carrion should be highly sought after, generating strong competition. We therefore predicted that hermit crabs would be equally motivated for carrion regardless of its source (mussel or gastropod), so that the amount of aggression in the test period would not differ between the gastropod and the mussel conditions. Finally, we also explored whether crabs that were relatively larger than their competitors in the same aggregations would show higher levels of aggression, which might enable them to access more carrion.

To test our predictions, we performed two separate sets of analyses. Our first analysis focused on the behavior of the entire aggregation, summing aggressive behaviors across all individuals in an aggregation. In this analysis, we compared the total amount of aggression in two ways: (1) across different conditions (rock vs gastropod vs mussel) and (2) between the baseline and test periods of the same trials within a condition. When we found significant differences in the behavior of the aggregation, post hoc tests were run to determine the source of the difference. As the data deviated from normality even after log transformation (Shapiro-Wilk tests, baseline data: $\mathrm{W}=0.7946, P<0.001$; test data: $\mathrm{W}=0.9261, P<0.005)$, nonparametric KruskallWallis tests were used when comparing across conditions, and Wilcoxon-signed rank tests were used to compare data within trials. Bonferroni corrections were employed when the total and the specific measures of aggression were measured on the same data.

Our second analysis focused on different individuals within the same aggregation. A linear mixed model (LMM) was used to examine the relationship between the level of aggression a crab exhibited and its size. To avoid having to break crabs out of their shell to measure their body size, we used shell size as a proxy for body size (in 
Table 2. Levels of Pagurus samuelis aggression during experimental baseline and test periods examining effects of the addition of carrion on crab behavior across rock, gastropod, and mussel conditions.

\begin{tabular}{lcccccccc}
\hline & \multicolumn{3}{c}{ Across baseline periods } & & \multicolumn{3}{c}{ Across test periods } \\
\cline { 2 - 3 } \cline { 7 - 8 } Aggression type & $F$ & df & & $P$ & & $F$ & df & $P$ \\
\hline Total aggression & 3.056 & 2 & & 0.217 & & 20.34 & 2 & $<\mathbf{0 . 0 0 1}$ \\
Leg strikes & 0.830 & 2 & 0.667 & & 24.84 & 2 & $<\mathbf{0 . 0 0 1}$ \\
Claw strikes & 0.623 & 2 & 0.733 & & 4.27 & 2 & 0.129 \\
Attempted leg strikes & $\dagger$ & $\dagger$ & $\dagger$ & & 8.07 & 2 & $\mathbf{0 . 0 1 8}$ \\
Attempted claw strikes & 0.635 & 2 & 0.743 & & 4.47 & 2 & 0.122 \\
Piggybacking & 2.390 & 2 & & 0.305 & & 0.06 & & 0.972 \\
\hline
\end{tabular}

Note: Bolded boxes show where significant differences exist between the experimental conditions, after Bonferroni corrections. $\uparrow$ No occurrences of attempted leg strikes in any baseline trial.

our study, population shell size and body size correlate well; Laidre unpubl data; see also Tran et al. 2014, Souza et al. 2015).

The data were log transformed and modelled with a Gaussian error structure to correct for overdispersion. Our full model assessed whether levels of aggression during the test period were influenced by the weight of the flesh dropped in during the experiment, the baseline levels of aggression, the test condition, and crab size. Trial ID was added as a random effect because the measures of aggression within each aggregation were non-independent. Starting with the full model, we conducted backwards stepwise elimination by comparing changes in AIC values to determine the final model (see Online Appendix 1 for model selection). Factors were retained if their exclusion increased the model's AIC value by at least 2 (Zuur et al. 2009). The fit of the "best" model was assessed by calculating the coefficient of determination $\left(R^{2}\right)$. The effect direction and estimated influence of each covariate in the "best" model is reported in the text. All data analyses were conducted in R (R Core Team 2012). The LMM was implemented with the lme4 package, the $R^{2}$ calculations with the MuMIm package in $\mathrm{R}$.

\section{RESULTS}

Qualitative Behavior.-Once a carrion source was provided, crabs competed vigorously to access the flesh, repeatedly picking at and eating the meat with their claws while simultaneously trying to knock others away from their feeding location with their legs. "Piggybacking" (a behavior used to investigate conspecifics' shells) was rare and did not differ in occurrence across any of the conditions (Table 2). Moreover, no shell evictions occurred during any of the experiments. Crabs' behavior was thus consistent exclusively with a motivation to feed, not to acquire a new shell.

Behavior of Entire Aggregations.-Between the baseline and the test period, overall levels of aggression significantly increased for both the gastropod and the mussel flesh additions (Fig. 1, Table 3). In contrast, there was no change in overall levels of aggression between the baseline and the test period for the rock condition (Table 3). Thus, carrion (but not a control object) was able to spark elevated aggression within aggregations.

During the baseline period, there was no difference across the three conditions in the overall level of aggression (Kruskall Wallis test: $F=3.056, P=0.217$ ) or in 


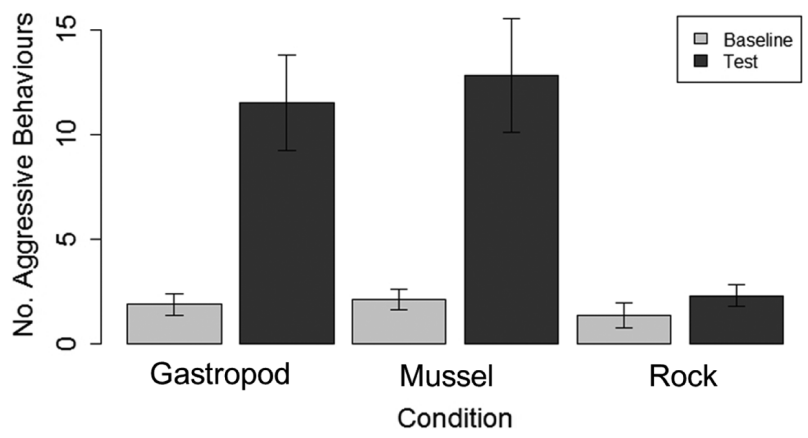

Figure 1. Overall levels of Pagurus samuelis aggression during experimental baseline and test periods examining effects of the addition of carrion on crab behavior. Error bars are standard error, and sample size is $n=20$ for mussel, $n=20$ for gastropod, and $n=19$ for rock.

specific measures of aggression (Fig. 2, Table 2). In contrast, during the test period across the three conditions, there was a significant difference in the overall level of aggression $(F=20.34, P<0.001$; Fig. 1$)$, including in leg strikes $(F=24.84, P<0.001)$ and in attempted leg strikes $(F=8.07, P=0.018)$. Compared to the rock condition, both carrion conditions produced significantly higher levels of overall aggression, as well as leg strikes and attempted leg strikes, during the test period. Post hoc analysis (Table 4) further revealed that during the test period the gastropod and mussel flesh

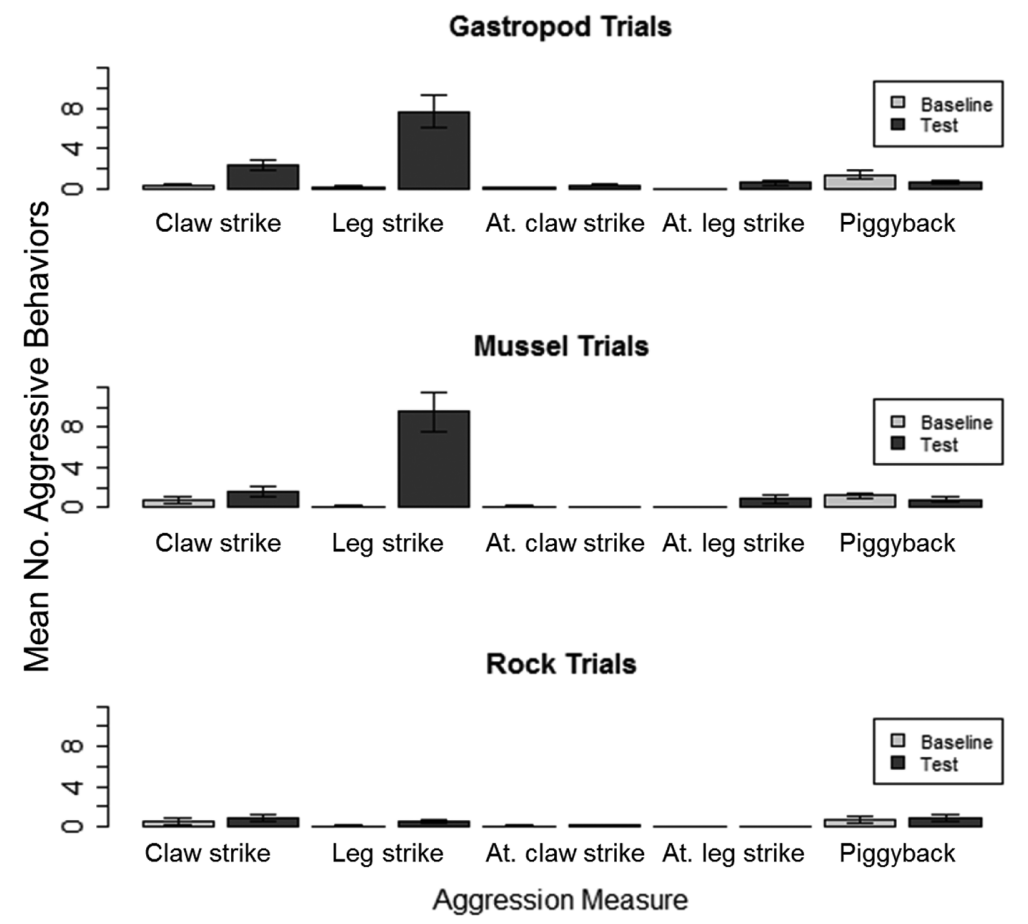

Figure 2. Specific measures of Pagurus samuelis aggression during the experimental baseline and test periods examining effects of the addition of carrion on crab behavior. "At." = attempted. Error bars are standard error, and sample size is $n=20$ for mussel, $n=20$ for gastropod, and $n$ $=19$ for rock. 
Table 3. Test statistics comparing aggression of Pagurus samuelis behavior between the baseline and the test period within each condition examining effects of the addition of carrion on crab behavior.

\begin{tabular}{lrc}
\hline Aggression type & $V$ & $P$ \\
\hline Gastropod condition & 8.0 & $<\mathbf{0 . 0 0 1}$ \\
Total & 4.3 & $<\mathbf{0 . 0 0 1}$ \\
Leg strikes & 20.0 & $<\mathbf{0 . 0 0 5}$ \\
Claw strikes & 50.0 & 0.082 \\
Attempted leg strikes & 64.0 & 0.212 \\
Attempted claw strikes & 148.0 & 0.153 \\
Piggybacking & & \\
Mussel condition & 4.5 & $<\mathbf{0 . 0 0 1}$ \\
Total & 3.0 & $<\mathbf{0 . 0 0 1}$ \\
Leg strikes & 65.0 & 0.153 \\
Claw strikes & 45.5 & 0.052 \\
Attempted leg strikes & 114.0 & 0.562 \\
Attempted claw strikes & 140.0 & 0.211 \\
Piggybacking & & \\
Total & 41.0 & $0.040^{*}$ \\
Leg strikes & 52.5 & 0.157 \\
Claw strikes & 46.5 & 0.072 \\
Attempted leg strikes & 95.0 & 0.512 \\
Attempted claw strikes & 86.5 & 0.562 \\
Piggybacking & 86.5 & 0.660 \\
\hline
\end{tabular}

Note: Because the data contained zero values, the test statistics and $P$-values are estimates based on 10,000 repetitions that added small amounts of noise to break ties for each test. *After a Bonferroni correction, this value is no longer significant.

additions did not differ in overall levels of aggression, or in leg strikes or attempted leg strikes. Thus, aggregations competed equally for either source of carrion.

Behavior of Specific Individuals within Aggregations.-Crabs occupying larger shells were more likely to demonstrate aggressive behaviors [LMM: $n=165$, coefficient estimate $($ Est $)=1.21$, SE 0.31]. The amount of aggression observed during the baseline period helped predict the amount of aggression in the test period (LMM: Est $=0.18$, SE 0.05), but this pattern was not condition specific. The model confirmed the results found in the analysis of entire aggregations, showing that test levels of aggression were comparatively higher in the gastropod (LMM: Est $=0.61$, SE 0.19) and mussel flesh additions (LMM: Est $=0.84$, SE 0.19) compared to the rock addition. The specific weight of the carrion did not have an effect on the level of aggression during the test period (see Online Appendix 1 for changes in AIC values between models). The "best" model had an $R^{2}$ of 0.483 .

Table 4. Results of post-hoc Wilcoxon rank sum comparing aggression of Pagurus samuelis, examining effects of the addition of carrion on behavior.

\begin{tabular}{lccc}
\hline Aggression type & Gastropod vs mussel & Gastropod vs rock & Mussel vs rock \\
\hline Overall aggression & $P=1.00$ & $P=0.001$ & $P<0.001$ \\
Leg strikes & $P=1.00$ & $P<0.001$ & $P<0.001$ \\
Attempted leg strikes & $P=1.00$ & $P=0.025$ & $P=0.017$ \\
\hline
\end{tabular}

Post-hoc analysis was run only on behavioral measures that showed significant differences. $P=1.00$ does not mean $P=1$. 


\section{DISCUSSION}

Despite the fact that hermit crabs aggregate in search of food resources (Ramsay et al. 1996, Laidre 2010, 2013, Laidre and Greggor 2015), relatively little work has looked at patterns of aggression and competition as hermit crabs compete over food (though see Allee and Douglis 1945, Laidre and Elwood 2008, Tran et al. 2014). The present study demonstrated that highly competitive fights over food occur among hermit crabs. Relative to baseline conditions, the addition of mussel and gastropod carrion significantly increased aggressive behavior, while the addition of a control object (a rock) did not. Moreover, when comparing between the test periods of different experimental conditions, similar levels of aggression occurred in both the mussel addition (which exclusively indicated food) and the gastropod addition (which may imply potential shell availability as well as food). Hermit crabs were thus strongly motivated to compete for eatable carrion, independent of an available shell resource.

Some studies have found that hermit crabs can differentiate between the scent of different types of carrion (e.g., Tran 2013, 2015) and even between different species of gastropod (Rittschof 1980a). In our study, hermit crabs rarely performed shellacquisition behaviors (e.g., piggybacking) and they also did not perform such behaviors more in the gastropod compared to the mussel addition, suggesting that they did not differ in motivation for carrion associated with usable shells vs carrion that is not. We suggest the hermit crabs did not respond differently to the gastropod and mussel additions in the present study for two reasons. First, we extracted fresh flesh from live mollusks, and did not treat the flesh with chemicals. Previous work treating carrion flesh with predatory digestive enzymes (e.g., trypsin) found that hermit crabs differentiated trypsin-treated flesh from fresh flesh, especially when the flesh was from gastropods, which indicates available shells (Rittschof 1980b). The method of preparing flesh may therefore be critical in enabling crabs to differentiate types of carrion.

A second and perhaps more important reason crabs in our study did not respond differently to gastropod and mussel carrion was likely related to their high level of hunger. Irrespective of any shell-related cues, aggregations of crabs in both the gastropod and mussel conditions showed strong and equal motivation to obtain a valuable protein-rich food resource. Indeed, leg strikes were the most prevalent aggressive behavior we measured in both the gastropod and the mussel additions, increasing more than any other behavior in the competitive test periods. Crabs' use of leg strikes against conspecifics was linked to the fact that both their claws were often fully engaged in gripping and tearing at the flesh, so that they could eat. Our results suggest that food competition may potentially be a more pressing fitness concern for hermit crabs than shell competition, at least under some ecological conditions.

Interestingly, prior studies that starved hermit crabs for increasing durations (Laidre and Elwood 2008) found that longer-starved crabs showed a boosted motivation for carrion and sought it out more intensely. Internal physiological state, in addition to local ecological context, may thus shape individuals' motivations for different resources, like food vs shells. In the present study, crabs were not starved and were instead tested immediately after being gathered from the wild, which suggests that in nature hermit crabs may often be hungry. It remains unclear, however, the extent to which increased acts of aggression and competitive behavior enable individual crabs to outcompete conspecifics and obtain proportionally more food. In our 
study, larger individuals (at least with respect to shell size) performed more aggressive acts; but future studies are still needed to measure the actual body size of these more competitive individuals and to determine whether individuals that are more competitive actually ended up acquiring more carrion during intraspecific fights for food. Notably, since fights for food may also occur in contexts where multiple hermit crab species are present in the same aggregation (Kaiser 1998), higher levels of interspecific aggression could also enable sympatric species to outcompete one another or differentially specialize on specific food resources (cf. Tran 2014, Tran et al. 2014). Further experiments on both intra- and inter-specific fights for food could shed light on these questions.

Hermit crabs have emerged as a model system for understanding general theories of signaling (Laidre 2007, 2009, Laidre and Elwood 2008) and fighting behavior (Hazlett 1970, Vance 1972, Elwood and Neil 1992, Briffa and Elwood 2001). Indeed, because their competitive interactions can be readily quantified and because the motivational factors influencing shell acquisition can be readily manipulated, hermit crabs offer a tractable empirical system for testing broader ideas about competition and evolution (Lancaster 1988). We suggest that the continued exploration of food fighting behavior in hermit crabs adds an extra layer of motivational complexity that will ultimately enable further insights into the evolution of competition behavior.

\section{ACKNOWLEDGMENTS}

We thank the Bodega Marine Laboratory and the California Department of Fish and Wildlife for permission to conduct this research. We are especially grateful to J Sones, K Brown, and E Sanford at Bodega, and to T Herrlinger at Berkeley for their helpful advice, discussion, and logistical support. Research was supported by funding from the Miller Institute at Berkeley to ML.

\section{Literature Cited}

Allee WC, Douglis MB. 1945. A dominance order in the hermit crab, Pagurus longicarpus Say. Ecology. 26:411-412. http://dx.doi.org/10.2307/1931663

Bollay M. 1964. Distribution and utilization of gastropod shells by the hermit crabs Pagurus samuelis, Pagurus granosimanus, and Pagurus hirsutiusculus at Pacific Grove California. Veliger. 6(suppl):71-76.

Briffa M, Elwood RW. 2001. Decision rules, energy metabolism and vigour of hermit-crab fights. Proc Biol Sci. 268:1841-1848. http://dx.doi.org/10.1098/rspb.2001.1752

Britton JC, Morton B. 1994. Marine carrion and scavengers. Oceanogr Mar Biol Annu Rev. 32:369-434.

de Souza ECF, Turra A, Leite FPP, Gorman D. 2015. Intra-specific competition drives variation in the fundamental and realized niches of the hermit crab, Pagurus criniticornis. Bull Mar Sci. 91:343-361. http://dx.doi.org/10.5343/bms.2015.1005

Elwood R, Neil S. 1992. Assessments and decisions, a study of information gathering by hermit crabs. London: Chapman \& Hall. p. i-ix, 1-192.

Hazlett BA. 1970. The effect of shell size and weight on the agonistic behavior of a hermit crab. Z Tierpsychol. 27:369-374. http://dx.doi.org/10.1111/j.1439-0310.1970.tb01878.x

Hazlett B. 1981. The behavioral ecology of hermit crabs. Annu Rev Ecol Syst. 12:1-22. http:// dx.doi.org/10.1146/annurev.es.12.110181.000245

Hazlett BA, Rittschof D, Bach CE. 1996. Interspecific shell transfer by mutual predation site attendance. Anim Behav. 51:589-592. http://dx.doi.org/10.1006/anbe.1996.0062 
Kaiser MJ. 1998. Can fisheries influence interspecific competition in sympatric populations of hermit crabs? J Nat Hist. 32:521-531. http://dx.doi.org/10.1080/00222939800770281

Kellogg C. 1976. Gastropod shells, a potentially limiting resource for hermit crabs. J Exp Mar Biol Ecol. 22:101-111. http://dx.doi.org/10.1016/0022-0981(76)90112-X

Laidre ME. 2007. Vulnerability and reliable signaling in conflicts between hermit crabs. Behav Ecol. 18:736-741. http://dx.doi.org/10.1093/beheco/arm040

Laidre ME. 2009. How often do animals lie about their intentions? An experimental test. Am Nat. 173:337-346. http://dx.doi.org/10.1086/596530

Laidre ME. 2010. How rugged individualists enable one another to find food and shelter: field experiments with tropical hermit crabs. Proc Biol Sci. 277:1361-1369. http://dx.doi. org/10.1098/rspb.2009.1580

Laidre ME. 2011. Ecological relations between hermit crabs and their shell-supplying gastropods: constrained consumers. J Exp Mar Biol Ecol. 397:65-70. http://dx.doi.org/10.1016/j. jembe.2010.10.024

Laidre ME. 2012a. Niche construction drives social dependence in hermit crabs. Curr Biol. 22:R861-R863. http://dx.doi.org/10.1016/j.cub.2012.08.056

Laidre ME. 2012b. Homes for hermits: temporal, spatial and structural dynamics as transportable homes are incorporated into a population. J Zool. 288:33-40. http://dx.doi. org/10.1111/j.1469-7998.2012.00921.x

Laidre ME. 2013. Foraging across ecosystems: diet diversity and social foraging spanning aquatic and terrestrial ecosystems by an invertebrate. Mar Ecol. 34:80-89. http://dx.doi. org/10.1111/j.1439-0485.2012.00527.x

Laidre ME, Elwood RW. 2008. Motivation matters: cheliped extension displays in the hermit crab, Pagurus bernhardus, are honest signals of hunger. Anim Behav. 75:2041-2047. http:// dx.doi.org/10.1016/j.anbehav.2007.11.011

Laidre ME, Trinh R. 2014. Unlike terrestrial hermit crabs, marine hermit crabs do not prefer shells previously used by conspecifics. Crustaceana. 87:856-865. http://dx.doi. org/10.1163/15685403-00003320

Laidre ME, Greggor AL. 2015. Swarms of swift scavengers: ecological role of marine intertidal hermit crabs in California. Mar Biol. 162:969-977. http://dx.doi.org/10.1007/ s00227-015-2639-3

Lancaster I. 1988. Pagurus bernhardus (L.) an introduction to the natural history of hermit crabs. Field Stud. 7:189-238.

McGuire BM, Williams JD. 2010. Utilization of partially predated snail shells by the hermit crab Pagurus longicarpus Say, 1817. Mar Biol. 157:2129-2142. http://dx.doi.org/10.1007/ s00227-010-1478-5

McLean R. 1983. Gastropod shells: a dynamic resource that helps shape benthic community structure.J Exp Mar Biol Ecol.69:151-174. http://dx.doi.org/10.1016/0022-0981(83)90065-5

McLean RB. 1974. Direct shell acquisition by hermit crabs from gastropods. Experientia. 30:206-208. http://dx.doi.org/10.1007/BF01927738

Morris RH, Abbott DP, Haderlie EC. 1980. Intertidal invertebrates of California. Stanford: Stanford University Press. ix, $690 \mathrm{p}$.

Morton B, Yuen W. 2000. The feeding behavior and competition for carrion between two sympatric scavengers on a sandy shore in Hong Kong: the gastropod, Nassarius festivus (Powys) and the hermit crab, Diogenes edwardsii (De Haan). J Exp Mar Biol Ecol. 246:1-29. http:// dx.doi.org/10.1016/S0022-0981(99)00170-7

R Core Team. 2012 R: a language and environment for statistical computing. R Foundation for Statistical Computing, Vienna Austria. Available from: http://www.r-project.org

Ramsay K, Kaiser MJ, Huges RN. 1996. Changes in hermit crab feeding patterns in response to trawling disturbance. Mar Ecol Prog Ser. 144:63-72. http://dx.doi.org/10.3354/meps144063

Ramsay K, Kaiser MJ, Hughes RN. 1997. A field study of intraspecific competition for food in hermit crabs (Pagurus bernhardus). Estuar Coast Shelf Sci. 44:213-220. http://dx.doi. org/10.1006/ecss.1996.0213 
Rittschof D. 1980a. Chemical attraction of hermit crabs and other attendants to simulated gastropod predation sites. J Chem Ecol. 6:103-118. http://dx.doi.org/10.1007/BF00987531

Rittschof D. 1980b. Enzymatic production of small molecules attracting hermit crabs to simulated gastropod predation sites. J Chem Ecol. 6:665-675. http://dx.doi.org/10.1007/ BF00987677

Scully EP. 1979. The effects of gastropod shell availability and habitat characteristics on shell utilization by the intertidal hermit crab Pagurus longicarpus. J Exp Mar Biol Ecol. 37:139152. http://dx.doi.org/10.1016/0022-0981(79)90091-1

Tran MV. 2013. Divergent reactions to olfactory foraging cues between two ecologically similar, sympatric hermit crab species. J Crustac Biol. 33:512-518. http://dx.doi. org/10.1163/1937240X-00002154

Tran MV. 2014. Coexisting generalist scavengers occupy different feeding niches. Mar Biol. 161:2589-2596. http://dx.doi.org/10.1007/s00227-014-2530-7

Tran MV. 2015. Behavioral reactions to novel food odors by intertidal hermit crabs. Behav Processes. 113:35-40. http://dx.doi.org/10.1016/j.beproc.2014.12.015

Tran MV, O'Grady M, Colborn J, Van Ness K, Hill W. 2014. Aggression and food resource competition between sympatric hermit crab species. PLoS One. 9(3):e91823. http://dx.doi. org/10.1371/journal.pone.0091823

Tricarico E, Bertocchi S, Brusconi S, Antonio Chessa L, Gherardi F. 2009. Shell recruitment in the Mediterranean hermit crab Clibanarius erythropus. J Exp Mar Biol Ecol. 381:42-46. http://dx.doi.org/10.1016/j.jembe.2009.09.001

Tricarico E, Gherardi F. 2006. Shell acquisition by hermit crabs: which tactic is more efficient? Behav Ecol Sociobiol. 60:492-500. http://dx.doi.org/10.1007/s00265-006-0191-3

Turra A, Denadai MR, Leite FPP. 2005. Predation on gastropods by shell-breaking crabs: effects on shell availability to hermit crabs. Mar Ecol Prog Ser. 286:279-291. http://dx.doi. org $/ 10.3354 /$ meps 286279

Vance RR. 1972. The role of shell adequacy in behavioral interactions involving hermit crabs. Ecology. 53:1075-1083. http://dx.doi.org/10.2307/1935419

Zuur AF, Ieno EN, Walker NJ, Saveliev AA, Smith GM. 2009. Mixed effects models and extensions in ecology. New York: Springer-Verlag.

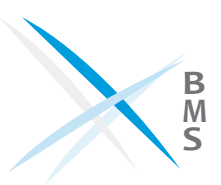


